\title{
High NOTCH activity induces radiation resistance in non small cell lung cancer
}

\author{
Citation for published version (APA):
}

Theys, J., Yahyanejad, S., Habets, R., Span, P., Dubois, L., Paesmans, K., Kattenbeld, B., Cleutjens, J., Groot, A. J., Schuurbiers, O. C. J., Lambin, P., Bussink, J., \& Vooijs, M. (2013). High NOTCH activity induces radiation resistance in non small cell lung cancer. Radiotherapy and Oncology, 108(3), 440-445. https://doi.org/10.1016/j.radonc.2013.06.020

\section{Document status and date:}

Published: 01/09/2013

DOI:

10.1016/j.radonc.2013.06.020

Document Version:

Publisher's PDF, also known as Version of record

\section{Document license:}

Taverne

\section{Please check the document version of this publication:}

- A submitted manuscript is the version of the article upon submission and before peer-review. There can be important differences between the submitted version and the official published version of record.

People interested in the research are advised to contact the author for the final version of the publication, or visit the DOI to the publisher's website.

- The final author version and the galley proof are versions of the publication after peer review.

- The final published version features the final layout of the paper including the volume, issue and page numbers.

Link to publication

\footnotetext{
General rights rights.

- You may freely distribute the URL identifying the publication in the public portal. please follow below link for the End User Agreement:

www.umlib.nl/taverne-license

Take down policy

If you believe that this document breaches copyright please contact us at:

repository@maastrichtuniversity.nl

providing details and we will investigate your claim.
}

Copyright and moral rights for the publications made accessible in the public portal are retained by the authors and/or other copyright owners and it is a condition of accessing publications that users recognise and abide by the legal requirements associated with these

- Users may download and print one copy of any publication from the public portal for the purpose of private study or research.

- You may not further distribute the material or use it for any profit-making activity or commercial gain

If the publication is distributed under the terms of Article $25 \mathrm{fa}$ of the Dutch Copyright Act, indicated by the "Taverne" license above, 
Molecular radiobiology

\title{
High NOTCH activity induces radiation resistance in non small cell lung cancer
}

\author{
Jan Theys ${ }^{\mathrm{a}, *, 1}$, Sanaz Yahyanejad ${ }^{\mathrm{a}, 1}$, Roger Habets ${ }^{\mathrm{a}}$, Paul Span ${ }^{\mathrm{b}}$, Ludwig Dubois ${ }^{\mathrm{a}}$, Kim Paesmans ${ }^{\mathrm{a}}$, \\ Bo Kattenbeld ${ }^{\mathrm{b}}$, Jack Cleutjens ${ }^{\mathrm{c}}$, Arjan J. Groot ${ }^{\mathrm{a}}$, Olga C.J. Schuurbiers ${ }^{\mathrm{d}}$, Philippe Lambin ${ }^{\mathrm{a}}$, Jan Bussink ${ }^{\mathrm{b}}$, \\ Marc Vooijs a,*
}

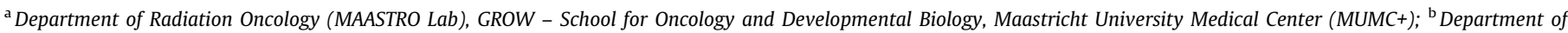
Radiation Oncology, Radboud University Medical Center, Nijmegen; ${ }^{\mathrm{C}}$ Department of Pathology, Maastricht University Medical Center (MUMC+); ${ }^{\mathrm{d}}$ Department of

Pulmonary Diseases, Radboud University Medical Center, Nijmegen, The Netherlands

\section{A R T I C L E I N F O}

\section{Article history:}

Received 12 April 2013

Received in revised form 19 June 2013

Accepted 21 June 2013

Available online 25 July 2013

\section{Keywords:}

$\mathrm{NOTCH}$

NSCLC

Radiation

Hypoxia

\begin{abstract}
A B S T R A C T
Background and purpose: Patients with advanced NSCLC have survival rates $<15 \%$. The NOTCH pathway plays an important role during lung development and physiology but is often deregulated in lung cancer, making it a potential therapeutic target. We investigated NOTCH signaling in NSCLC and hypothesized that high NOTCH activity contributes to radiation resistance.

Materials and methods: NOTCH signaling in NSCLC patient samples was investigated using quantitative RT-PCR. H460 NSCLC cells with either high or blocked NOTCH activity were generated and their radiation sensitivity monitored using clonogenic assays. In vivo, xenograft tumors were irradiated and response assessed using growth delay. Microenvironmental parameters were analyzed by immunohistochemistry. Results: Patients with high NOTCH activity in tumors showed significantly worse disease-free survival. In vitro, NOTCH activity did not affect the proliferation or intrinsic radiosensitivity of NSCLC cells. In contrast, xenografts with blocked NOTCH activity grew slower than wild type tumors. Tumors with high NOTCH activity grew significantly faster, were more hypoxic and showed a radioresistant phenotype. Conclusions: We demonstrate an important role for NOTCH in tumor growth and correlate high NOTCH activity with poor prognosis and radioresistance. Blocking NOTCH activity in NSCLC might be a promising intervention to improve outcome after radiotherapy.
\end{abstract}

(c) 2013 Elsevier Ireland Ltd. All rights reserved. Radiotherapy and Oncology 108 (2013) 440-445
Lung cancer is the leading cause of cancer mortality worldwide with overall 5 -year survival rates $<15 \%$. Non small cell lung cancer (NSCLC) is the most common type and found in $85 \%$ of cases. There is an urgent need for novel approaches to combat NSCLC [1]. Targeting the NOTCH signaling pathway is promising in this respect. The NOTCH signaling pathway is a highly conserved pathway that controls cell fate decisions in mammals [2]. NOTCH proteins are cell surface transmembrane receptors that interact with adjacent cells expressing membrane bound ligands. Ligand binding triggers two consecutive proteolytic cleavages resulting in the release of the cytosolic NOTCH intracellular domain (NICD) to the nucleus where it activates gene transcription. Targets of canonical NOTCH signaling include not only negative transcriptional regulators of the HES and HEY-family, but also oncogenes such as Ras or Myc [3]. In the developing lung, NOTCH signaling controls proximal-

\footnotetext{
* Corresponding authors. Address: Maastricht University Medical Center+, Universiteitssingel 50/23, PO Box 616, 6200MD Maastricht, The Netherlands.

E-mail addresses: jan.theys@maastrichtuniversity.nl (J. Theys), marc.vooijs@maastrichtuniversity.nl (M. Vooijs).

${ }^{1}$ These authors contributed equally to this work.
}

distal cell fates during branching morphogenesis and the pathway is vital to maintain adult lung physiology [4]. Perturbations in the NOTCH signaling pathway are frequent in NSCLC by deregulated expression or via oncogenic mutation [5]. Activating mutations in NOTCH1, similar to those found in T-ALL, occur in 10\% of NSCLC whereas in $\sim 30 \%$ of cases, loss of NUMB1, a negative regulator of NOTCH, is observed [6]. In a large cohort of 355 NSCLC patients, high NOTCH1 expression was a negative prognostic factor [7]. Aberrant NOTCH expression is also linked to pathways frequently implicated in NSCLC, such as amplified EGFR [8] and mutant KRas [9].

Standard of care for advanced NSCLC patients includes chemoradiotherapy. Unfortunately, resistance toward radiation often contributes to therapy failure, an observation which in breast cancer [10] and glioblastoma [11] has been linked to a cancer stem cell (CSC)/NOTCH phenotype. Little is known about the role of NOTCH in radiation response for NSCLC. Given the (pre)clinical data that implicate the NOTCH pathway in NSCLC and the observation that resistance toward radiotherapy in various tumor types implicates NOTCH signaling, we examined whether aberrant NOTCH signaling 
contributes to diminished radiation response in NSCLC. Our findings indicate that NOTCH promotes tumor growth and correlates with a radioresistant phenotype in NSCLC in vivo and we propose that targeting NOTCH in NSCLC patients may increase therapy response and improve outcome.

\section{Materials and methods}

Patients

Patients who underwent a curative resection for stage I, II and resectable stage IIIA, cN0-1 NSCLC at the Radboud University Nijmegen Medical Centre between January 2002 and December 2008 , of whom fresh frozen lung resection biopsies and/or pretreatment 18FDG-PET-scans were available, were included in this study ( $n=119$ ) (for detailed patient characteristics see [12] and Supplementary Table 1 ). Patients who received experimental neo-adjuvant treatment were excluded $(n=5)$. Twenty seven fresh frozen samples were not suitable for evaluation due to sampling error (absence of tumor tissue, presence of inflammatory tissue or necrosis) and two biopsies could not be retrieved. For treatment outcome analysis, three patients with incomplete anatomical resections based on unexpected stage IIIB/IV (TNM 7th edition) were excluded.

\section{Cell lines and reagents}

H460 (lung carcinoma) cells were grown in RPMI (PAA) supplemented with $10 \%$ FBS (PAA). H460 cells were transduced with viral particles as described [13] by transfecting MIGR1-N1 $\triangle$ EGFP $\left(\mathrm{NOTCH}^{\mathrm{hi}}\right)$, MSCV-hMAML1(12-74)-GFP $\left(\mathrm{NOTCH}^{\mathrm{lo}}\right)$ or MIGR1 (control, MIGR1 is a MSCV derivative with IRES-GFP) (plasmids were kind gift of J. Aster, Boston [14]). For NOTCH transcriptional assays, a pGL4.24-12×CSL luciferase reporter was transfected [15] together with pGL4.74 TK-hRL (Promega) for normalization. $\gamma$-Secretase inhibitor (GSI) dibenzazepine (DBZ) was used at a final concentration of $200 \mathrm{nM}$ or vehicle (DMSO) as a control. Dual luciferase activity was measured on a Fluostar Omega plate reader (BMG Labtech).

\section{Western blotting and real time quantitative PCR}

SDS-PAGE, Western blot and qRT-PCR were performed according to standard protocols [16]. Total RNA from cell lines and patient samples was isolated using RNeasy (Qiagen) and Nucleospin RNAII (BIOKE), respectively. Antibodies used are listed in Supplementary Table 2. Primers used are listed in Supplementary Table 3.

\section{Proliferation assays and clonogenic survival analysis}

For proliferation assays, cells were cultured in 24-well plates in triplicate and phase contrast images were taken using the IncuCyte $^{\mathrm{TM}}$ at $4 \mathrm{~h}$ intervals for 4-5 days. Data were analyzed using IncuCyte $^{\mathrm{TM}}$ cell proliferation assay software. Clonogenic assays were performed as described [17].

\section{In vivo xenograft studies}

Animal experiments were in accordance with national guidelines. $3 \times 10^{6} \mathrm{NOTCH}^{\mathrm{hi}}$, NOTCH ${ }^{\mathrm{lo}}$ or control tumor cells were subcutaneously injected in the flank of NMRI-nu mice. Animals were randomly assigned to control or irradiation group. Tumor volumes were measured $3 \times /$ week in three orthogonal diameters. When tumors reached $\sim 250 \mathrm{~mm}^{3}$, tumors were irradiated with a single dose of $10 \mathrm{~Gy}$ ( $15 \mathrm{MeV} \mathrm{e}^{-}$) using a linear accelerator (Varian). Response was assessed by calculating the time for each tumor to reach $4 \times$ the treatment starting volume. The hypoxia marker pimonidazole hydrochloride $(60 \mathrm{mg} / \mathrm{kg}$, i.p.) was injected $1 \mathrm{~h}$ before euthanizing the animals.

\section{Immunohistochemistry}

Formalin-fixed, paraffin-embedded tumors were cut in $5 \mu \mathrm{m}$ sections and immunohistochemical stainings performed according to standard protocol (Suppl. Table 2 for antibodies). Negative controls were obtained by omitting the primary antibody. Quantification of Ki67 was performed by determining the number of Ki67 positive nuclei as a proportion of total number of nuclei in 10 representative fields of viable tumor tissue across multiple tumors per group. Hypoxia was assessed in whole tumor sections with pimonidazole as a marker. Hypoxia and necrosis areas were quantified using Leica Qwin morphometry software.

\section{Statistical analysis}

Statistical analysis was carried out using GraphPad Prism (5.0b for Mac OS). Log-Rank (Mantel Cox) or Mann-Whitney tests were performed to determine statistical significance between groups.

\section{Results}

High tumor NOTCH activity correlates with worse prognosis in patients with NSCLC

To address if NOTCH activation is involved in NSCLC, we analyzed the expression profile of NOTCH receptors, ligands and target genes in NSCLC patient samples. Our data show heterogeneous expression of NOTCH pathway components across the samples (Fig. 1A). To investigate the prognostic relevance of these findings, we correlated the observed gene expression levels with patient disease-free survival (DFS), calculated from the date of surgery to the date of relapse. DFS was significantly worse in patients with high tumor mRNA levels of NOTCH1 $(p=0.025)$, JAG2 $(p=0.025)$ or HES1 $(p=0.013)$ (Suppl. Fig. 1). DFS of NSCLC patients whose tumors exhibited high levels of all three was significantly worse than other patients $(p=0.006)$ (Fig. 1B). These data indicate broad activation of the NOTCH pathway in human NSCLC with a worse outcome in patients with the highest expression.

\section{NOTCH activity does not affect proliferation or radiation sensitivity in vitro}

To investigate the role of deregulated NOTCH signaling in NSCLC, we transduced $\mathrm{H} 460$ cells to have constitutive high, normal or low NOTCH activity, respectively. GFP+ cells were sorted by FACS analysis (Suppl. Fig. 2) and lysates analyzed with cleavage specific antibodies for activated NOTCH1 and GFP expression by Western Blot (Fig. 2A). Differential NOTCH transcriptional activity was confirmed using reporter assays (Fig. 2B) and target gene expression analysis (Suppl. Fig. 3). Although blocking of NOTCH activity has been shown to affect proliferation in certain tumors [18], we found that increased or decreased NOTCH activity did not significantly change in vitro proliferation rates (Fig. 2C). Since we are specifically interested in the effect of aberrant $\mathrm{NOTCH}$ expression in NSCLC in radiotherapy (RT) resistance, we examined the response to ionizing radiation. Intriguingly, cells with hyperactivated or attenuated NOTCH activity showed similar surviving fractions as control cells (Fig. 2D) indicating that the NOTCH signaling pathway does not affect the intrinsic radiosensitivity of the cells. 

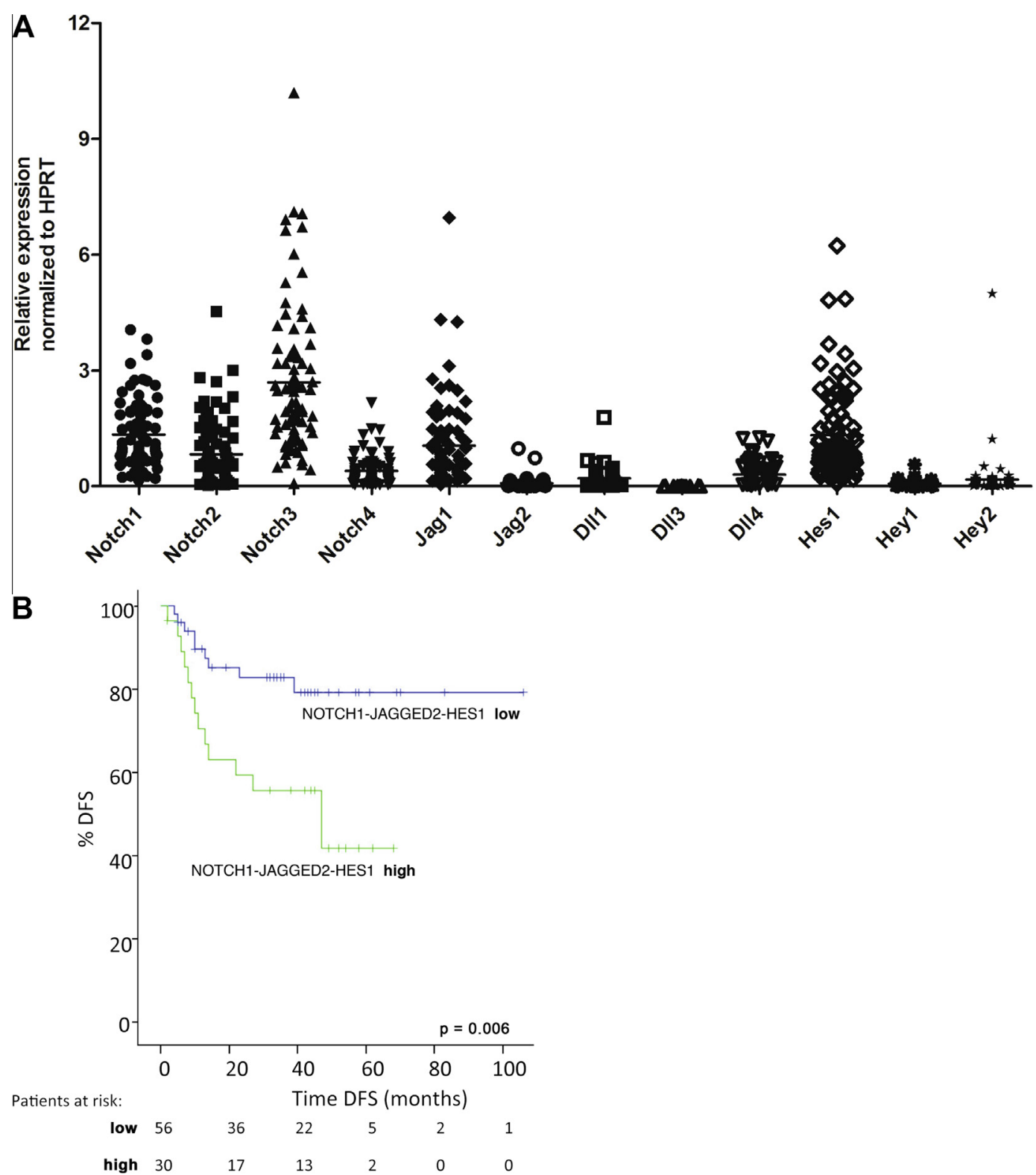

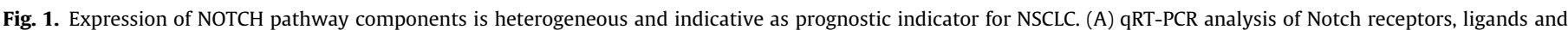
target genes in 89 NSCLC tumors. Values are normalized to HPRT. (B) Kaplan-Meier curves showing DFS of the same patient population.

NOTCH activity enhances tumor growth and decreases radiation sensitivity in vivo

Since the lack of a biological effect of NOTCH on proliferation or radiation sensitivity in vitro could be caused by the absence of the naïve tumor microenvironment, we next addressed the role for NOTCH signaling in growth and response to radiotherapy of NSCLC xenografts in vivo. Tumors were established from control, NOTCH1 and DNMAML1 overexpressing H460 cells and tumor growth rate evaluated (Fig. 3A). NOTCH target gene expression in the tumors mirrored observations from the H460_DNMAML and H460_N1 $\Delta \mathrm{E}$ H460 cell lines (Suppl. Fig. 4A). N1 $\Delta$ E-expressing tumors $\left(\mathrm{NOTCH}^{\text {hi }}\right)$ grew significantly faster $(p<0.05$, average doubling time 6.3 days) than the H460_ctrl tumors (average doubling time 8.5 days) whereas the doubling time of DN_MAML-expressing $\mathrm{NOTCH}^{\text {lo }}$ tumors was significantly higher $(p<0.05$, average doubling time 14.3 days) (Fig. 3B). This differential growth behavior was also reflected in a significantly different Ki67 proliferation index across the groups (Fig. 3C). To investigate the effect of differen- tial NOTCH activity on the microenvironment, we quantified the hypoxic and necrotic area fraction in entire tumor sections using immunohistochemical analysis. A significantly higher hypoxic fraction $(p<0.01)$ was found in NOTCH ${ }^{\text {hi }}$ tumors compared to control and NOTCH ${ }^{\text {lo }}$ tumors. Similar results were obtained when the necrotic areas were excluded during the analysis (not shown). $\mathrm{NOTCH}^{\text {lo }}$ tumors were significantly more necrotic $(p<0.05)$ (Fig. 3C). Overall, these data indicate the importance of the microenvironment when assessing NOTCH-related effects and correlate NOTCH activity with proliferation in vivo.

Because NOTCH activity correlates with worse outcome, we investigated if high NOTCH activity negatively affected the response to radiotherapy, part of standard care for NSCLC. Although radiation caused a significant growth delay in both $\mathrm{NOTCH}^{\mathrm{wt}}$ and $\mathrm{NOTCH}^{\text {hi }}$ tumors $(p<0.05$, compared to non-irradiated group), $\mathrm{NOTCH}^{\text {hi }}$ tumors were significantly more resistant than control tumors $(p=0.01$ ) (Fig. 3D). The average time to reach $4 \times$ the starting volume following RT was 36.2 days for H460_ctrl and 16.9 days for 
A
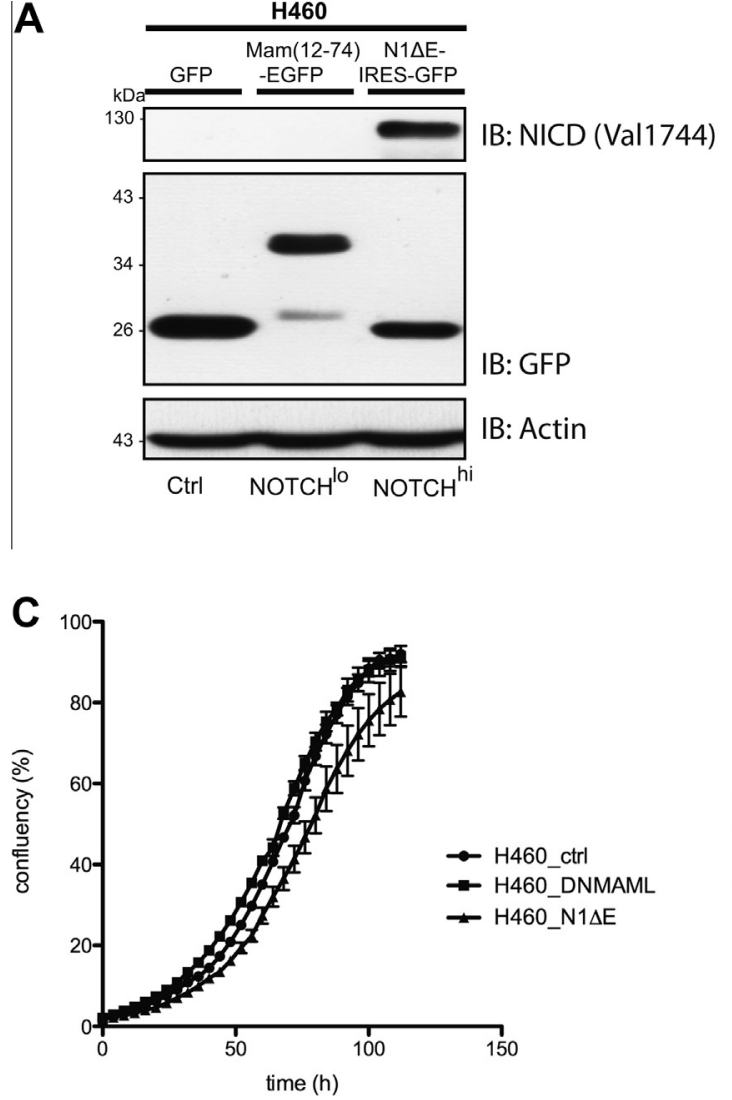

B

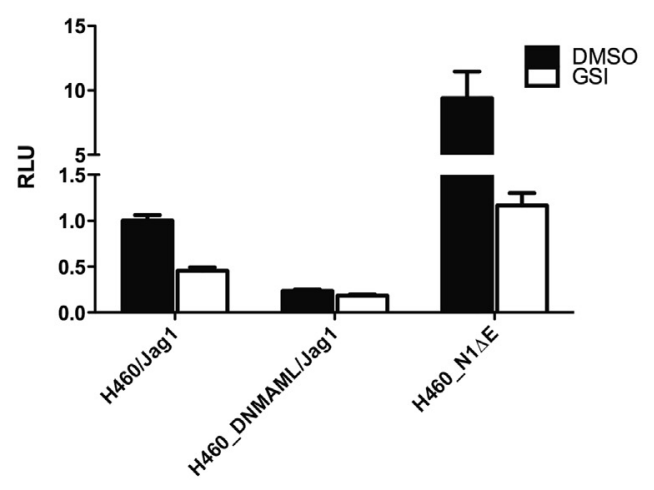

D

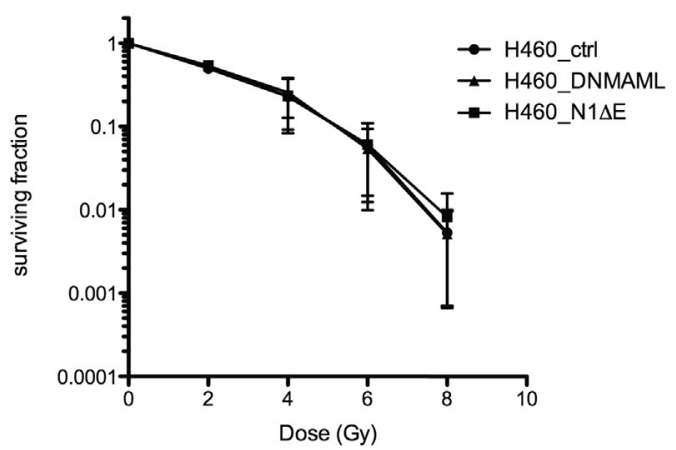

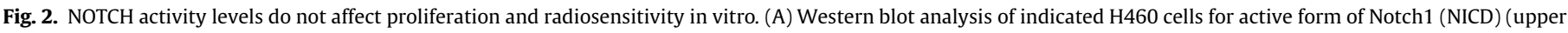

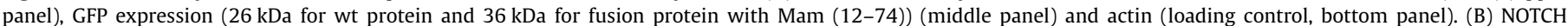

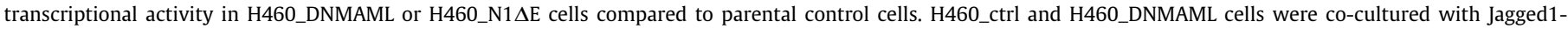

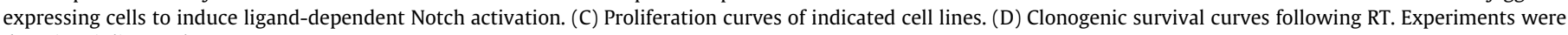
done in triplicate. Shown are average \pm SEM.

$\mathrm{NOTCH}^{\text {hi }}$ tumors (Fig. 3E and Suppl. Fig. 4B). This was not a consequence of the increased proliferation in NOTCH ${ }^{\text {hi }}$ tumors, as the specific tumor growth delay (corrected for growth rate) was also significantly different $(p=0.02)$. In the NOTCH ${ }^{\text {hi }}$ tumors, the hypoxic fraction further increased upon radiation $(p<0.05)$, a phenomenon not observed in the irradiated H460_ctrl tumors. In these latter tumors the hypoxic fraction remained unaltered upon radiation, yet the necrotic fraction increased $(p<0.05)$ (Fig. $3 F$ ).

\section{Discussion}

In the current study, we show that high tumor NOTCH activity is associated with decreased overall survival in NSCLC patients. We demonstrate that inhibition of the NOTCH cascade slows tumor growth in vivo while ectopic activation enhances the growth rate. High proliferation rate is a hallmark of cancer and meta-analysis in lung cancer has reported high Ki67 to be an adverse prognostic indicator [19]. Our observation that high NOTCH expression induces resistance to radiotherapy is important, as radiotherapy is standard of care for the majority of NSCLC [1]. Whereas we have only addressed the effect of hyperactive NOTCH on a single radiation dose, it will be important to investigate how ectopic NOTCH signaling affects the response to clinically relevant fractionated therapy as well. Intriguingly, neither proliferation nor response to radiation was different when assessed in vitro. This indicates that the outcome of aberrant NOTCH activity in solid tumors is highly context-dependent and is determined by interactions with the microenvironment.

As overall survival rates are very poor for NSCLC, improvement of local tumor control is urgently needed. Our data propose that patient stratification based on NOTCH tumor activity could be an important first step toward selection of patients that may benefit from the addition of NOTCH inhibition strategies. Our clinical data are in line with previous observations showing that high NOTCH activation in NSCLC results in worse prognosis [7]. Interestingly, Donnem et al. showed the poorest survival for patients co-expressing high levels of NOTCH1 and VEGF-A. This mutual overexpression could well reflect a higher level of hypoxia in these neoplasms, which is in agreement with our observations of a higher hypoxic fraction in NOTCH ${ }^{\text {hi }}$ tumors. Since hypoxia leads to treatment resistance, the increased hypoxic fraction in $\mathrm{NOTCH}^{\text {hi }}$ tumors is consistent with their radioresistant phenotype. Multiple observations link hypoxia and NOTCH signaling. Hypoxia activates Delta-NOTCH signaling in endothelial cells during tumor angiogenesis via VEGF [20]. Recently, Liu et al. showed that blocking NOTCH signaling with anti-Dll4 mAb's in head and neck or colon xenografts alone or in combination with RT delayed tumor growth by promoting non-functional angiogenesis and extensive tumor necrosis [21]. Although the exact mechanism(s) responsible for the radioresistant phenotype here remain to be established, the extensive necrosis we observed in tumors with blocked NOTCH activation, points in the same direction. Our future studies will further elaborate on the underlying mechanisms. In NSCLC, overexpression of NOTCH1 promotes survival under hypoxia [22] 
A

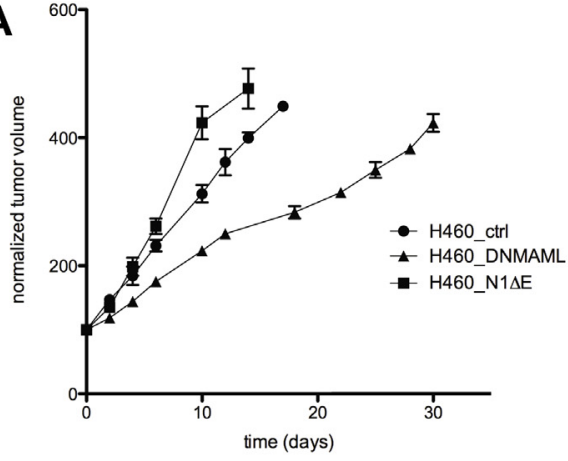

B

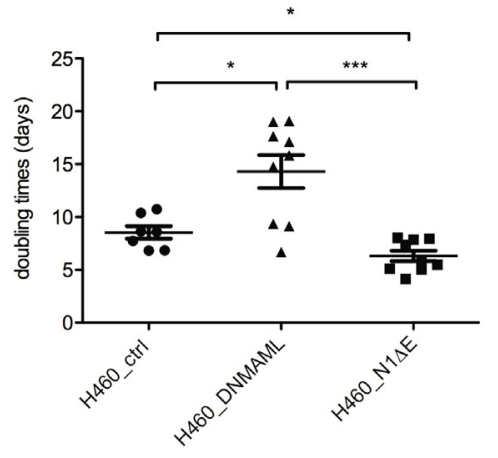

C

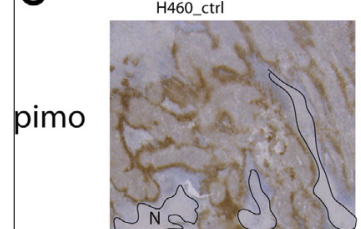

Ki67

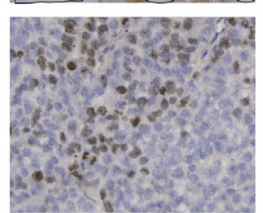

H460_DNMAML

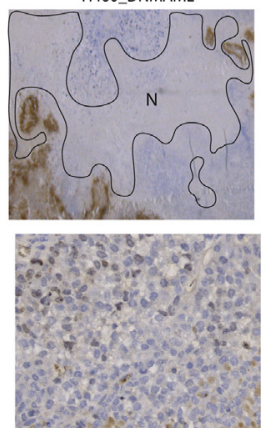

H460_N1deltaE
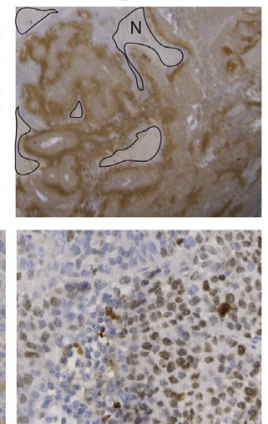
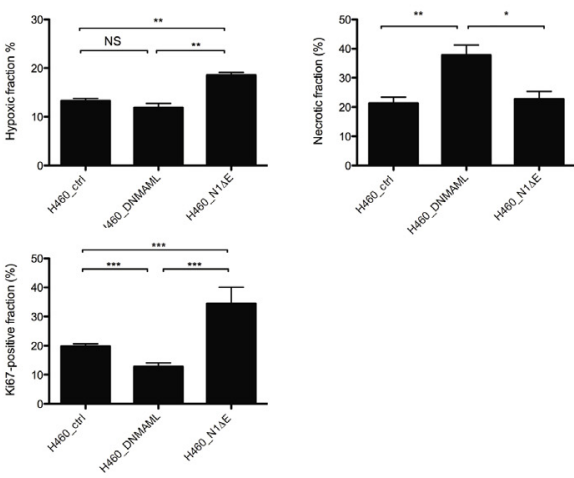

E
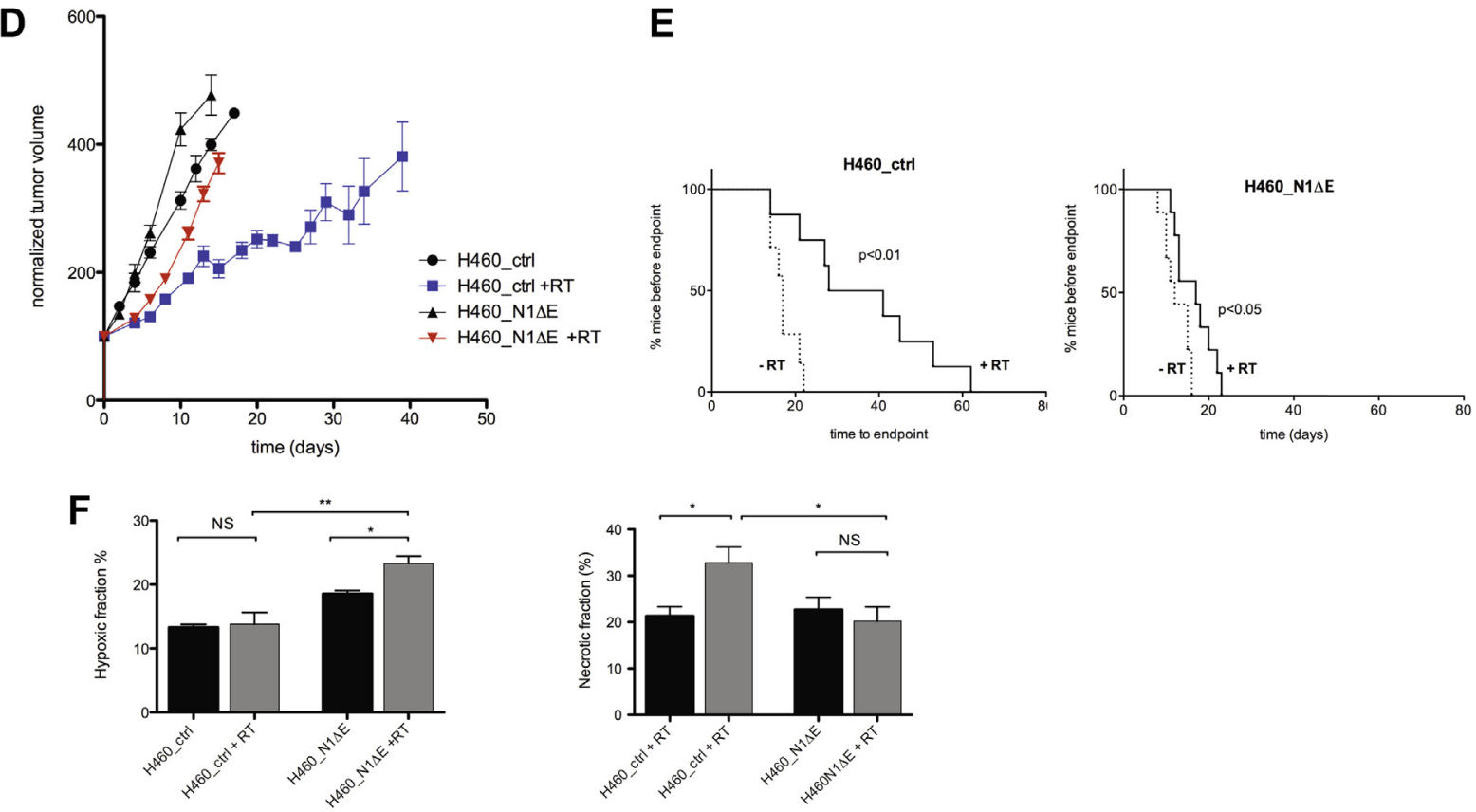

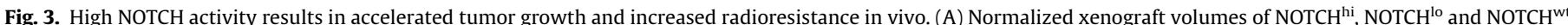

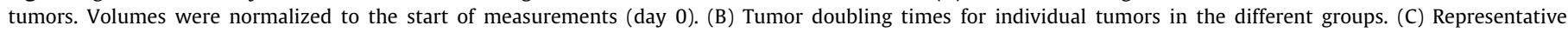

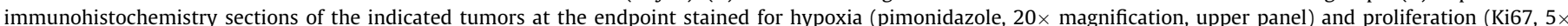

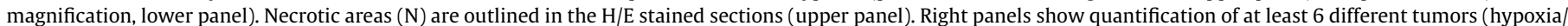

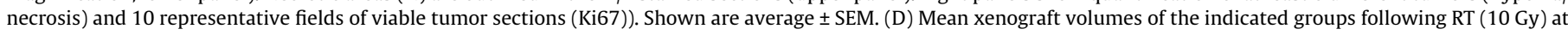

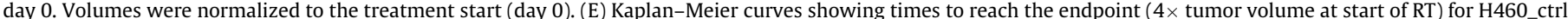

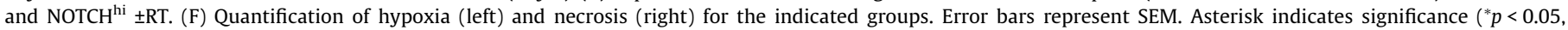
${ }^{* *} p<0.01$ and $\left.{ }^{* * *} p<0.001\right)$, NS, not significant.

whereas hypoxia in turn, leads to upregulation of the NOTCH pathway, inducing NOTCH dependent migration and invasion [23]. Interestingly, cancer stem cells (CSCs) have been shown to reside in the hypoxic tumor microenvironment [24]. A significant correla- tion between the SC marker ALDH1A1 and poor prognosis was found in a cohort of $>200$ NSCLC samples. The proportion of these ALDH1A1+ cells was reduced upon NOTCH inhibition, showing their NOTCH-dependency [25]. Also CD133+ cells isolated from pri- 
mary NSCLC have tumor initiating capacity compared to CD133and an active NOTCH cascade [26]. In both breast cancer [10] and glioma [11], this $\mathrm{CSC} / \mathrm{NOTCH}$ phenotype has been directly linked to radiation resistance. Whether CSCs also contribute to the decreased radiation response in NSCLC as in our study is currently under investigation. From a treatment point of view, it is promising that synergism has also been shown between $\mathrm{NOTCH}$ inhibition and commonly used chemotherapeutics in NSCLC [26,27].

Overall, ample data suggest that NOTCH is an attractive target for cancer treatment. Not surprisingly, there are currently over 50 registered phase I/II clinical trials using NOTCH inhibitors. We demonstrate an important role for NOTCH in tumor growth and correlate high NOTCH activity with poor prognosis and radioresistance. Blocking high tumor NOTCH activity might thus be potentially promising to improve NSCLC outcome after radiotherapy.

\section{Conflict of interest}

None.

\section{Acknowledgements}

R. Habets, A. J. Groot and M. Vooijs are supported by the ERC (ERC starting grant \#208259 to MV). We acknowledge financial support from the Dutch Cancer Society (KWF Grant UM 20063514).

\section{Appendix A. Supplementary data}

Supplementary data associated with this article can be found, in the online version, at http://dx.doi.org/10.1016/j.radonc.2013. 06.020.

\section{References}

[1] De Ruysscher D, Belderbos J, Reymen B, et al. State of the art radiation therapy for lung cancer 2012: a glimpse of the future. Clin Lung Cancer 2013;14:89-95.

[2] Artavanis-Tsakonas S, Muskavitch M. Notch: the past, the present, and the future. Curr Top Dev Biol 2010;92:1-29.

[3] Miele L, Golde T, Osborne B. Notch signaling in cancer. Curr Mol Med 2006;6:905-18.

[4] Morimoto M, Nishinakamura R, Saga Y, Kopan R. Different assemblies of Notch receptors coordinate the distribution of the major bronchial Clara, ciliated and neuroendocrine cells. Development 2012;139:4365-73.

[5] Ranganathan P, Weaver K, Capobianco A. Notch signalling in solid tumours: a little bit of everything but not all the time. Nat Rev Cancer 2011;11:338-51.

[6] Westhoff B, Colaluca IN, D'Ario G, et al. Alterations of the Notch pathway in lung cancer. Proc Natl Acad Sci USA 2009;106:22293-8.
[7] Donnem T, Andersen S, Al-Shibli K, Al-Saad S, Busund L-T, Bremnes R. Prognostic impact of Notch ligands and receptors in nonsmall cell lung cancer: coexpression of Notch-1 and vascular endothelial growth factor-A predicts poor survival. Cancer 2010;116:5676-85.

[8] Baumgart A, Seidl S, Vlachou P, et al. ADAM17 regulates epidermal growth factor receptor expression through the activation of Notch1 in non-small cell lung cancer. Cancer Res 2010;70:5368-78.

[9] De La OJ, Emerson LL, Goodman JL, et al. Notch and Kras reprogram pancreatic acinar cells to ductal intraepithelial neoplasia. Proc Natl Acad Sci USA 2008;105:18907-12.

[10] Sun Lei, Cabarcas Stephanie M, Farrar William L. Radioresistance and cancer stem cells: survival of the fittest. Carcinogen Mutagen 2011:21-81.

[11] Wang J, Wakeman TP, Lathia JD, et al. Notch promotes radioresistance of glioma stem cells. Stem Cells 2010;28:17-28.

[12] Meijer TW, Schuurbiers OC, Kaanders JH, et al. Differences in metabolism between adeno- and squamous cell non-small cell lung carcinomas: spatial distribution and prognostic value of GLUT1 and MCT4. Lung Cancer 2012;76:316-23.

[13] Theys J, Jutten B, Habets R, et al. E-cadherin loss associated with EMT promotes radioresistance in human tumor cells. Radiother Oncol 2011;99:392-7.

[14] Weng A, Nam Y, Wolfe M, et al. Growth suppression of pre-T acute lymphoblastic leukemia cells by inhibition of notch signaling. Mol Cell Biol 2003;23:655-64.

[15] van Tetering G, Bovenschen N, Meeldijk J, van Diest PJ, Vooijs M. Cleavage of Notch1 by granzyme B disables its transcriptional activity. Biochem J 2011:437:313-22.

[16] Theys J, Jutten B, Dubois L, et al. The deletion mutant EGFRvIII significantly contributes to stress resistance typical for the tumour microenvironment. Radiother Oncol 2009;92:399-404.

[17] Weppler S, Li Y, Dubois L, et al. Expression of EGFR variant vIII promotes both radiation resistance and hypoxia tolerance. Radiother Oncol 2007;83:333-9.

[18] Suwanjunee S, Wongchana W, Palaga T. Inhibition of gamma-secretase affects proliferation of leukemia and hepatoma cell lines through Notch signaling. Anticancer Drugs 2008;19:477-86.

[19] Martin B, Paesmans M, Mascaux C, et al. Ki-67 expression and patients survival in lung cancer: systematic review of the literature with meta-analysis. $\mathrm{Br} \mathrm{J}$ Cancer 2004:91:2018-25.

[20] Diez H, Fischer A, Winkler A, et al. Hypoxia-mediated activation of Dll4-NotchHey2 signaling in endothelial progenitor cells and adoption of arterial cell fate. Exp Cell Res 2007;313:1-9.

[21] Liu S, Bham S, Fokas E, et al. Delta-like ligand 4-notch blockade and tumor radiation response. J Natl Cancer Inst 2011;103:1778-98.

[22] Eliasz S, Liang S, Chen Y, et al. Notch-1 stimulates survival of lung adenocarcinoma cells during hypoxia by activating the IGF-1R pathway. Oncogene 2010;29:2488-98.

[23] Sahlgren C, Gustafsson MV, Jin S, Poellinger L, Lendahl U. Notch signaling mediates hypoxia-induced tumor cell migration and invasion. Proc Natl Acad Sci USA 2008;105:6392-7.

[24] Keith B, Simon MC. Hypoxia-inducible factors, stem cells, and cancer. Cell 2007;129:465-72.

[25] Sullivan JP, Minna JD, Shay JW. Evidence for self-renewing lung cancer stem cells and their implications in tumor initiation, progression, and targeted therapy. Cancer Metastasis Rev 2010;29:61-72.

[26] Bertolini G, Roz L, Perego P, et al. Highly tumorigenic lung cancer CD133+ cells display stem-like features and are spared by cisplatin treatment. Proc Natl Acad Sci USA 2009;106:16281-6.

[27] Domingo-Domenech J, Vidal SJ, Rodriguez-Bravo V, et al. Suppression of acquired docetaxel resistance in prostate cancer through depletion of notchand hedgehog-dependent tumor-initiating cells. Cancer Cell 2012;22:373-88. 